\title{
RANCANG BANGUN ALAT PRAKTIKUM PNEUMATIC DUA SILINDER MENGGUNAKAN DUA SHUTTLE VALVE
}

\author{
Ahmad Iskandar, Ali Rosyidin, Agus Tri Prasetyo \\ Program Studi Teknik mesin, Fakultas teknik, Universitas Muhammadiyah Tangerang, \\ Jl. Perintis Kemerdekaan I, No.33, Cikokol, Tangerang, Banten 15118, Indonesia
}

\begin{abstract}
ABSTRAK
Pneumatic pada masa sekarang ini memegang peranan penting dalam pengembangan teknologi otomatisasi, disamping hidrolik dan elektronik. Sistem otomatisasi peneumatic secara umum terdiri dari elemen sumber daya, elemen sinyal input, elemen pemroses sinyal, elemen pengendali sinyal dan elemen output (akuator). Untuk menunjang pengetahuan tentang pneumatic maka perlu adanya alat-alat pendukung praktikum pneumatic untuk menambah pengetahuan mahasiswa, salah satunya seperti alat peraga atau praktikum pneumatic.Tujuan dari pembuatan alat ini agar mahasiswa mampu merancang alat praktikum pneumatic dan juga dapat memberikan contoh aplikasi penggunaan sistem otomatisasi pneumatic pada dunia industri. Dalam proses pembuatan alat praktikum ini memiliki tahapan proses yang utama yaitu pembuatan desain rangkaian pneumatic dan kerangka meja alat pneumatic, persiapan bahan utama rangkaian pneumatic, pembuatan kerangka, dan pemasangan komponen pneumatic. Semua proses itu dilakukan dengan benar dan menghasilkan alat praktikum pneumatic yang berfungsi dengan baik.
\end{abstract}

Kata kunci :Simulator, pneumatic, otomatisasi.

\section{Pendahuluan}

Dijaman yang serba kekinian dan teknologi yang semakin canggih, maka diperlukan suatu alat penunjang yang memenuhi segala kriteria yang dibutuhkan oleh pasar sehingga alat tersebut akan berguna dan berfungsi dengan baik di pasaran.Dengan demikian kita dituntut untuk terus mengembangkan ide-ide tentang bagaimana peralatan sederhana dengan sistem yang serba praktis menjadi peralatan dengan sistem yang lebih komplek dan otomatis dapat mendukung proses produksi.

Sistem pneumatic biasanya dipergunakan untuk keperluan antara lain untuk mencekam benda kerja, menggeser benda kerja, memposisikan benda kerja, mengarahkan aliran barang ke berbagai arah. Penggunaan secara nyata pada industri antara lain untuk keperluan membungkus (verpacken), mengisi barang, mengatur distribusi barang, membuka dan menutup pintu, transportasi barang, memutar benda kerja, menumpuk dan menyusun barang, menahan dan menekan benda kerja. Melalui gerakan rotasi peneumatic dapat digunakan untuk mengebor, memotong, membentuk profil, dll. Untuk mendukung keperluan tersebut maka penulis mengambil judul "Rancang Bangun Alat Praktikum Pneumatic Dua Silinder Menggunakan Dua Shuttle Valve"

\section{Metodologi Penelitian}

Metode penelitian merupakan suatu langkah-langkah sistematis yang akan menjadi acuan dalam penyelesaian masalah (Sugiyono, 2004). Adapun tujuan Penelitian adalah penemuan, pembuktian dan pengembangan ilmu pengetahuan. Maka dari itu penelitian ini mengacu pada flow chart di bawah ini. Berikut pelaksanaannya secara sistematis dan berstruktur prosedur penelitian adalah :

1) Studi Literatur dan Observasivalve.

2) Tahapan Persiapan Mempersiapkan alat dan bahan, yang nantinya akan di pergunakan 
pada saat rancang bangun alat praktikum sudah dimulai

3) Desain Alat

Desain alat adalah gambaran awal yang dibuat dan di tentukan berdasarkan studi literatur dan observasi yang di dapat sebelumnya..

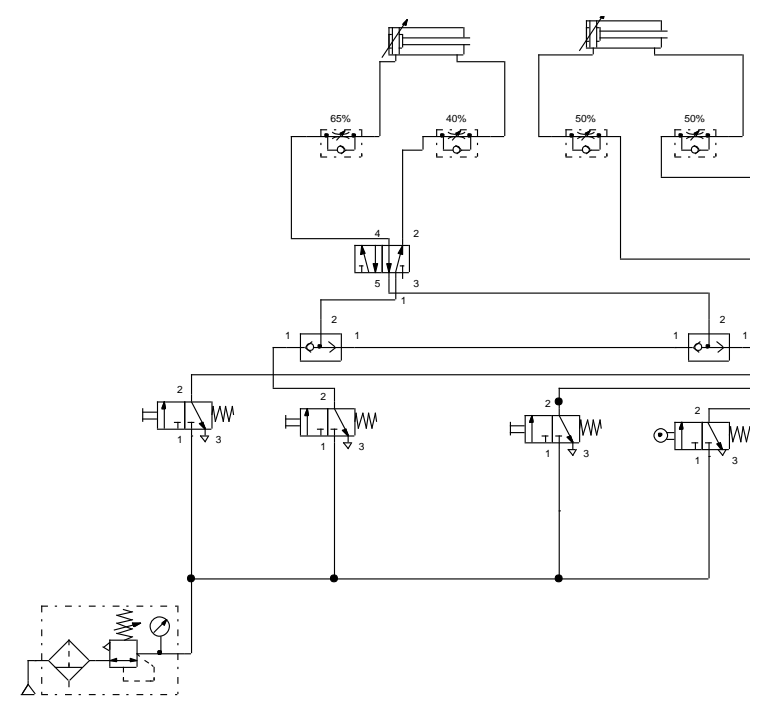

Gambar 1. Desain Alat Praktikum Peneumatic Dua Silinder Menggunakan Dua Shuttle Valve

4) Pembuatan Alat

Dalam proses pembuatan alat ini di awali membuat kerangka meja alat praktikum peneumatic.

5) Uji Coba Alat Praktikum Pneumatic

Dalam pengujian alat praktikum ini harus berfungsi sesuai desain yang sudah di buat sebelumnya.

6) Pembuatan Laporan

Setelah mempunyai data - data yang cukup dari hasil pengamatan dan perwujudan alat praktikum peneumatic, maka di buatlah laporan tentang alat praktikum pneumatic dua silinder menggunakan dua shuttle valve.

\section{Hasil Dan Pembahasan}

Dalam proses pembuatan alat praktikum pneumatic menggunakan dua shuttle valve ini mempunyai 3 tahapan proses. Berikut dibawah ini 3 tahapan proses tersebut:

1. Proses pembuatan kerangka

2. Proses pemasangan papan triplek putih

3. Proses pemasangan komponen rangkaian pneumatic

1). Proses Pembuatan Kerangka

a. Langkah pertama yang dilakukan untuk membuat kerangka meja alat praktikum peneumatic dua silinder menggunakan dua shuttle valve yaitu dengan membaca dan memahami desain gambar kerangka seperti di bawah ini.

b. Lagkah kedua lakukan pengukuran pada besi hollow sesuai dengan desain gambar kerangka yaitu dengan panjang ukuran $50 \mathrm{~cm}$ menjadi 5 bagian dan dengan ukuran panjang $20 \mathrm{~cm}$ menjadi 2 bagian.

Gambar 2. Desain Kerangka Meja Alat Praktikum Pneumatic

c. Langkah ketiga lakukan pengukuran pada besisikusesuai dengan desain gambar kerangka yaitu dengan ukuran panjang 100 $\mathrm{cm}$ hingga menjadi 5 bagian. Potong kembali besi siku dengan ukuran panjang $20 \mathrm{~cm}$ hingga menjadi 2 bagian.

d. Lanjutkan pengelasan pada bagian atas kerangka meja dengan menggunakan besi siku 
e. Lanjutkan membersihkan sisa sisa pengelasan yang menempel pada permukaan besi, setelah itu pasang roda pada bagian bawah kaki meja

2). Proses Pemasangan Papan Tiplek Putih

Pasang Papan triplek putih pada bagian atas dan tengah

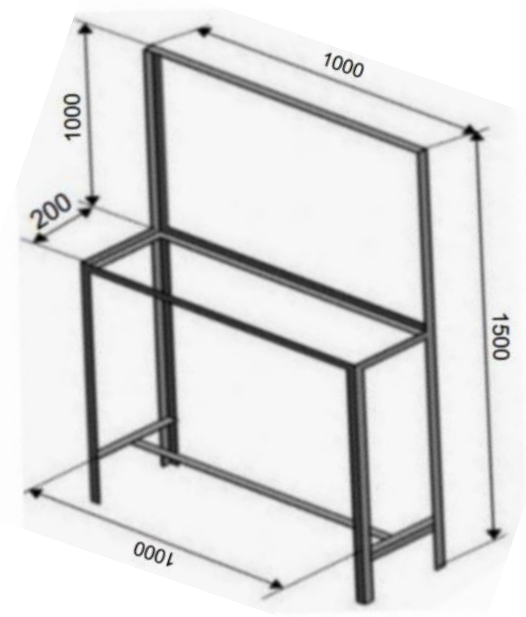

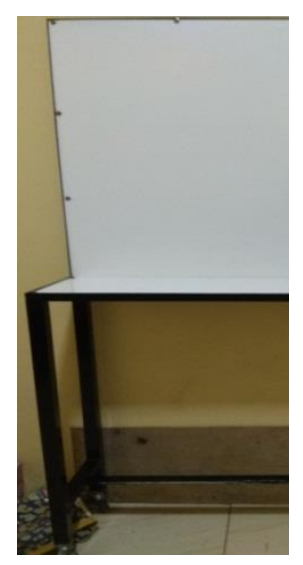

Gambar 3

Kerangka

Meja Yang

Sudah

Terpasang

Papan

Triplek Putih

3). Proses

Pemasangan

Komponen

Rangkaian

Pneumatic

Pasangkan komponen pneumatic pada meja praktikum yang meliputi regulator, push button, roll valve, shuttle valve, control valve 5/2, katup cekik dan silinder ganda menggunakan skrup lalu kencangkan dengan obeng . Setelah itu hubungkan antar komponen

pneumatic dengan selang pneumatic.

Berikut gambar alat praktikum:

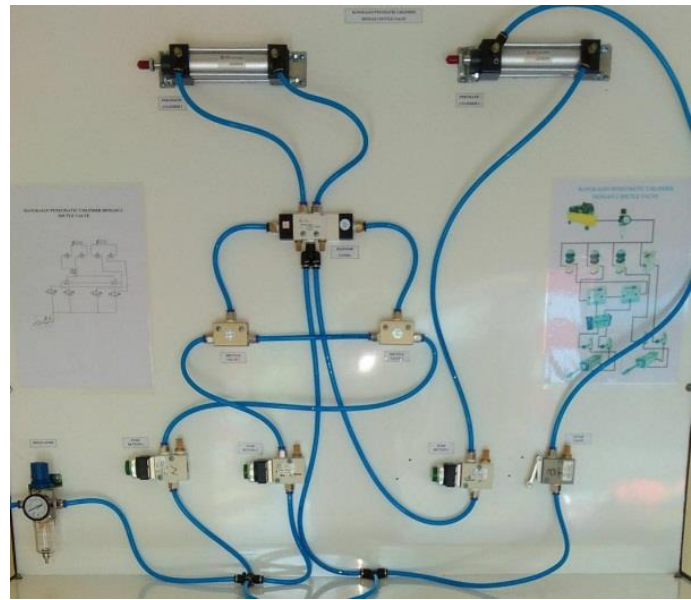

Gambar 4. Komponen Pneumatic Yang Sudah Terpasang

Setelah kita mengetahui cara pembuatan alat praktikum pneumatic dua silinder menggunakan dua shuttle valve, selanjutnya kita akan membahas cara kerja alat praktikum ini :

(1) Hidupkan kompresor dan biarkan beberapa menit hingga tangki udara kompresor penuh.

(2) Hubungkan selang regulator pneumaticpada saluran keluaran udara kompresor.

(3) Lalu buka knob regulator hingga tekanan udara menunjukan 5 bar.

(4) Setelah udara bertekanan siap maka tekan push button 1, udara masuk ke shuttle valve 1 dan control valve $5 / 2$ juga melelui katup cekik, maka silinder pneumatic 1 akan bergerak maju.

(5) Selanjutnya tekan push button 2, maka silinder pneumatic 1 akan bergerak mundur atau kembali seperti semula.

(6). Lanjutkan tekan push button 3, maka silinder pneumatic 2 akan bergerak maju, sementara silinder pneumatic 1 tidak bergerak. 
(7) Tekan roll valve 3/2, maka silinder pneumatic 2 akan bergerak mundur atau kembali seperti semula, sementara silinder pneumatic 1 tetap diam (tidak bergerak).

\section{Kesimpulan}

Dalam proses rancang bangun alat praktikum pneumatic dua silinder menggunakan dua shuttle valve mempunyai beberapa tahapan proses yang harus dilakukan diantaranya persiapan bahan kerangka meja alat praktikum yaitu besi hollow dan besi siku, alat perkakas pendukung yaitu mesin potong besi, mesin bor, mesin gerinda dan las listrik.
Persiapan komponen rangkaian pneumatic harus diperhatikan dan harus mengacu pada desain rangkaian pneumatic, karena jika ada yang tidak sesuai dengan desain rangakaian pneumatic rangkaian yang di buat tidak akan berfungsi sebagaimana mestinya.

Dalam rangkaian ini terdapat dua shuttle valve yang digunakan. Shuttle valve difungsikan sebagai katup pembuka udara bertekanan dari sisi kiri atau sisi kanan. Rangkaian ini merupakan rangkaian semi automatic karena memiliki 3 push button dan 1 roll valve yang dapat di aplikasikan pada industri saat ini.

\section{DAFTAR PUSTAKA}

H. Meixner, E. Saver, 1989, introduction to Electro-pneumatic, Esslingen : Festo Didactic KG

Peter Patient, Roy Pickup, Norman Powekk, 1985, Pengantar Ilmu Pneumatika,Alih Bahasa Alex Tri Kantjono Widodo, Jakarta : Gramedia

Parr, Andrew. 2003. Edisi Kedua, Hidrolika dan Pneumatik. Penerbit Erlangga

Stewart, Harry L. 1978.Hydraulic and Pneumatic Power for Production. Industrial Press. Vol 2 No 4 pp.21-36

Krist, Thomas. 1993. Dasar-Dasar Pneumatik. Penerbit Erlangga: Jakarta

Manipaz, Ehud. 1984 Essentials of Production and Operation Management. Prentice Hall. Inc Englewood Cliffs, New Jersey. USA

Hatuwe Noor Azmain. Perencanaan Instalasi Kontrol Pneumatik Menggunakan Metode Cascade . Pada Alat Pelumatan Tanah Liat Sebagai Bahan Dasar Batu Bata Merah. Jurnal TEKNOLOGI, Volume 9 Nomor 1, 2012; 969 - 977

Laksono Budi Arif . Analisa Modifikasi Timer Pneumatic Dan Proximity Menggunakan Timer Elektrik Pada Mesin Blowing Dan Mesin Filing .Jurnal Teknik Elektro . ISSN 2502-0986 Khalid Anhar . Rancang Bangun Simulasi sistem Pneumatik Untuk Pemindah Barang . Jurnal INTEKNA, Volume 16, No. 1, Mei 2016: 1 -100 . ISSN 1412-5609 